\title{
Dysfunction of Paracellin-1 by Dephosphorylation in Dahl Salt- Sensitive Hypertensive Rats
}

\author{
Akira IKARI ${ }^{1,2}$, Satomi MATSUMOTO2 ${ }^{2}$, Hitoshi HARADA ${ }^{2}$, Kuniaki TAKAGI ${ }^{2}$, \\ Masakuni DEGAWA ${ }^{3}$, Tadanobu TAKAHASHI ${ }^{1}$, Junko SUGATANI ${ }^{1}$, and \\ Masao MIWA ${ }^{1}$ \\ ${ }^{1}$ Department of Pharmaco-Biochemistry, ${ }^{2}$ Department of Environmental Biochemistry and Toxicology, and ${ }^{3}$ Department of Molecular \\ Toxicology and COE Program in the 21st Century, School of Pharmaceutical Sciences, University of Shizuoka, 52-1 Yada, Shizuoka \\ 422-8526, Japan
}

\begin{abstract}
A high-salt diet reduced the levels of renal cAMP content and serine-phosphorylated paracellin-1 in Dahl salt-sensitive hypertensive rats. In MDCK cells expressing paracellin-1, protein kinase $A$ inhibitor reduced the serine-phosphorylated
\end{abstract}

paracellin-1 and transepithelial $\mathrm{Mg}^{2+}$ transport, suggesting that a dephosphorylation of paracellin-1 induces the reduction of $\mathrm{Mg}^{2+}$ reabsorption in salt-sensitive hypertension.

Key words: paracellin-1, phosphorylation, hypertension.

\begin{abstract}
Arterial hypertension is the most common chronic disease in industrialized countries. Much evidence demonstrates a clear correlation between excess salt intake and the pathogenesis of hypertension [1-3]. The mechanism, however, by which excess salt intake elevates blood pressure is unknown. Dahl rats represent related strains that have an important difference in their response to a highsalt diet: the salt-sensitive (DS) strain develops hypertension, whereas the salt-resistant (DR) strain does not [4]. We [5] and others [6] reported that a high-salt diet in DS rats reduces the renal reabsorption of $\mathrm{Mg}^{2+}$. Conversely, dietary magnesium supplementation attenuates the blood pressure in deoxycorticosterone acetate (DOCA) salt-hypertensive rats $[7,8]$. These reports indicate that the body magnesium content is an important factor in salt-sensitive hypertension. In humans, several studies suggest that a decreased dietary intake of magnesium is associated with an increased risk of hypertension and that dietary magnesium supplementation lowers blood pressure [9-11].

Magnesium is an important cofactor for most of the ATPases. In the kidney, a magnesium deficiency eventually leads to low levels of calcium and potassium and to high levels of sodium and chloride [12]. This electrolytic imbalance may be a risk factor for hypertension. The body magnesium content is controlled by reabsorption through the renal epithelial cells. The renal $\mathrm{Mg}^{2+}$ filtrated in the glomeruli is predominantly reabsorbed by the paracellular
\end{abstract}

pathway in the thick ascending limb (TAL) of Henle [13]. Simon et al. [14] reported that paracellin-1 (named as claudin-16) is exclusively expressed in the cell-cell contact area, that is, the tight junction (TJ) of TAL, and it might play a critical role in the control of paracellular permeability for $\mathrm{Mg}^{2+}$ and $\mathrm{Ca}^{2+}$. Indeed, we revealed that paracellin-1 expression increases in the paracellular transport of divalent cations [15]. Several claudins have been reported to construct size and charge selective pores [1618]. However, the regulatory mechanisms of claudins expression are poorly understood.

In the present work, we show that a high-salt diet decreased the level of serine-phosphorylated paracellin- 1 in DS hypertensive rats. In Madin-Darby canine kidney (MDCK) cells expressing FLAG-tagged paracellin-1, paracellin-1 was phosphorylated at serine residue under control conditions. Protein kinase A (PKA) inhibitor reduced the level of serine-phosphorylated paracellin-1, transepithelial electrical resistance (TER), and transepithelial $\mathrm{Mg}^{2+}$ transport. In contrast, protein kinase C (PKC) inhibitor reduced TER, but it did not affect transepithelial $\mathrm{Mg}^{2+}$ transport. A high-salt diet decreased the cAMP content in the renal cortex of DS rats. Our data suggest that a decrease in cAMP content induces the reduction of serinephosphorylated paracellin-1 in DS hypertensive rats, resulting in a reduction of $\mathrm{Mg}^{2+}$ reabsorption.

Received on Jul 25, 2006; accepted on Sep 7, 2006; released online on Sep 9, 2006; doi:10.2170/physiolsci.SC008906 Abbreviations: MDCK, Madin-Darby canine kidney; DS, Dahl salt-sensitive; DR, Dahl salt-resistant; PKA, protein kinase A; PKC, protein kinase C; TER, transepithelial electrical resistance; $\mathrm{H}-89, \mathrm{~N}-[2-(p$-bromocinnamylamino)ethyl]-5-isoquinolinesulfonamide dihydrochloride.

Correspondence should be addressed to: Akira Ikari, Department of Pharmaco-Biochemistry, School of Pharmaceutical Sciences, University of Shizuoka, 52-1 Yada, Shizuoka, 422-8526 Japan. Tel: +81-54-264-5776, Fax: +81-54-264-5773,

E-mail: ikari@u-shizuoka-ken.ac.jp 


\section{Materials and methods}

Cell culture. Cell culture and transfection procedures for MDCK cells were described previously [15]. Stable transfectants of FLAG-tagged paracellin-1 were maintained in the continuous presence of the selecting drug $(0.5 \mathrm{mg} / \mathrm{ml} \mathrm{G} 418)$.

Preparation of membrane fraction and immunoprecipitation. Inbred male DR and DS rats (Japan Clea, Tokyo, Japan) were divided into two groups, and each group had free access to a normal salt (0.2\%) (DR-N and DS-N) or a high salt (8\%) diet (DR-H and DS-H) for four weeks (each group contains four rats). The brush border membrane (BBM) fractions of the renal cortex from DR and DS rats were prepared with $\mathrm{Mg}^{2+}$-EGTA precipitation methods [19]. The lysates of MDCK cells were prepared as described previously [15]. Protein concentrations were measured using the protein assay kit (Bio-Rad Laboratories, $\mathrm{CA}$ ), with bovine serum albumin as the standard. In immunoprecipitation, the samples were solubilized in a lysis buffer containing $150 \mathrm{mM} \mathrm{NaCl}, 0.5 \mathrm{mM}$ EDTA, $1 \%$ Triton $\mathrm{X}-100$, and $50 \mathrm{mM}$ Tris- $\mathrm{HCl}(\mathrm{pH} 8.0)$ and were incubated with protein G-Sepharose beads and anti-paracellin1 or anti-FLAG antibodies at $4^{\circ} \mathrm{C}$ for 120 min with gentle rocking. After centrifugation at $6,000 \times g$ for $1 \mathrm{~min}$, the pellet was washed four times with a lysis buffer. The BBM fractions of the renal cortex, the lysate fractions of MDCK cells, and immunoprecipitates were solubilized in a sample buffer for SDS-PAGE.

Immunoblotting. Immunoblotting was performed with commercial antibodies raised against FLAG, phosphoserine (Sigma, MO) and paracellin-1 (Santa Cruz, CA). The specific binding of antibodies was detected with peroxidase-conjugated secondary antibodies and visualized by enhanced chemiluminescence detection (Amersham Biosciences, Buckinghamshire, UK).

Measurement of paracellular permeability. MDCK cells expressing FLAG-tagged paracellin-1 were plated at confluent densities on Transwells with polyester membrane inserts (Corning Life Sciences, MA). TER was measured using a Millicell-ERS epithelial volt-ohmmeter (Millipore, MA). TER values (ohms $\times \mathrm{cm}^{2}$ ) were normalized by the area of the monolayer and calculated by subtracting the blank values from the filter and the bathing medium. The paracellular diffusion of FITC-dextran-4k from the apical to the basal compartments was measured with a Fluoroskan Ascent CF (Thermo Labosystems). The transepithelial transport of $\mathrm{Mg}^{2+}$ from the apical to the basal compartments was measured using xylidyl blue-I (XB-I). At time 0 , a transport buffer $(140 \mathrm{mM} \mathrm{NaCl}, 5.8 \mathrm{mM} \mathrm{KCl}$, $0.34 \mathrm{mM} \mathrm{Na}_{2} \mathrm{HPO}_{4}, 0.44 \mathrm{mM} \mathrm{KH} \mathrm{PO}_{4}, 1 \mathrm{mM} \mathrm{CaCl} 2,25$ $\mathrm{mM}$ glucose, and $20 \mathrm{mM}$ Hepes, $\mathrm{pH}$ 7.4) supplemented with $10 \mathrm{mM} \mathrm{Mg}^{2+}$ was poured into the filter well, and the reverse compartment was filled with the transport buffer without $\mathrm{Mg}^{2+}$. After incubation at $37^{\circ} \mathrm{C}$ for $60 \mathrm{~min}$, the reverse compartment media were collected and subjected to
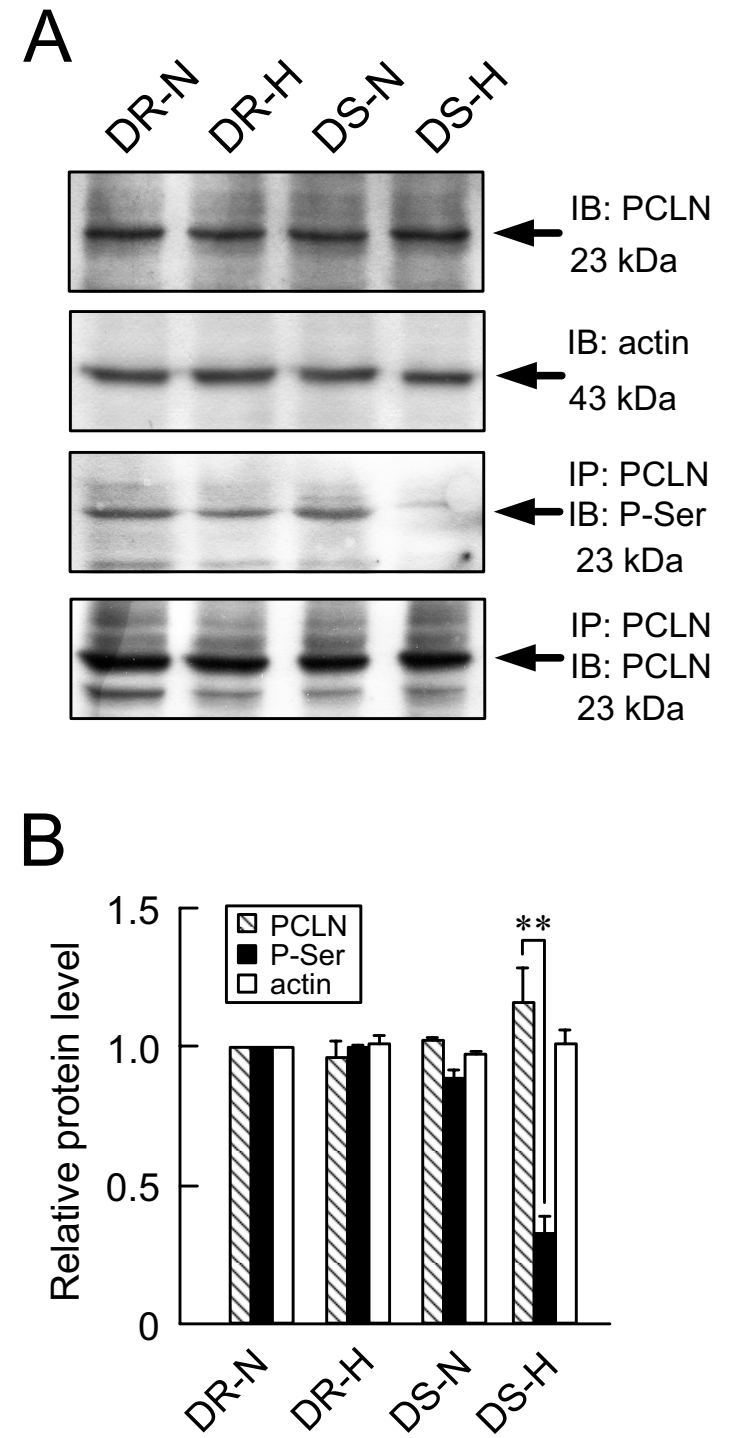

Fig. 1. Decrease of phosphorylated paracellin-1 by a high-salt diet. (A) The BBM fractions $(50 \mu \mathrm{g})$ were immunoblotted with anti-paracellin-1 (IB: PCLN) or anti-actin antibodies (IB: actin). The BBM fractions $(500 \mu \mathrm{g})$ were immunoprecipitated with protein G-Sepharose beads and anti-paracellin-1 antibody. The immune pellets were immunoblotted with antiphosphoserine (IP: PCLN, IB: P-Ser) or anti-paracellin-1 (IP: PCLN, IB: PCLN) antibodies. (B) The band densities of immunoblotting were expressed relative to the values in $\mathrm{DR}-\mathrm{H}$, DS$\mathrm{N}$, and DS-H of the value in DR-N. $n=3-4 .{ }^{* *} P<0.01$.

$\mathrm{Mg}^{2+}$ measurement. XB-I formed a $520 \mathrm{~nm}$ absorbance maximum complex on $\mathrm{Mg}^{2+}$ binding under alkaline conditions.

Measurement of CAMP content and protein phosphatase-2A. The homogenized renal cortex from DR and DS rats was centrifuged at $10,000 \times g$ for $60 \mathrm{~min}$, and supernatant was then collected. The supernatant was diluted appropriately and used for the assay. The cAMP content in renal cortex was assessed using the cAMP Assay Kit (Cayman Chemical Company, MI). The value of cAMP content was determined by absorbance at $405 \mathrm{~nm}$. The 
A
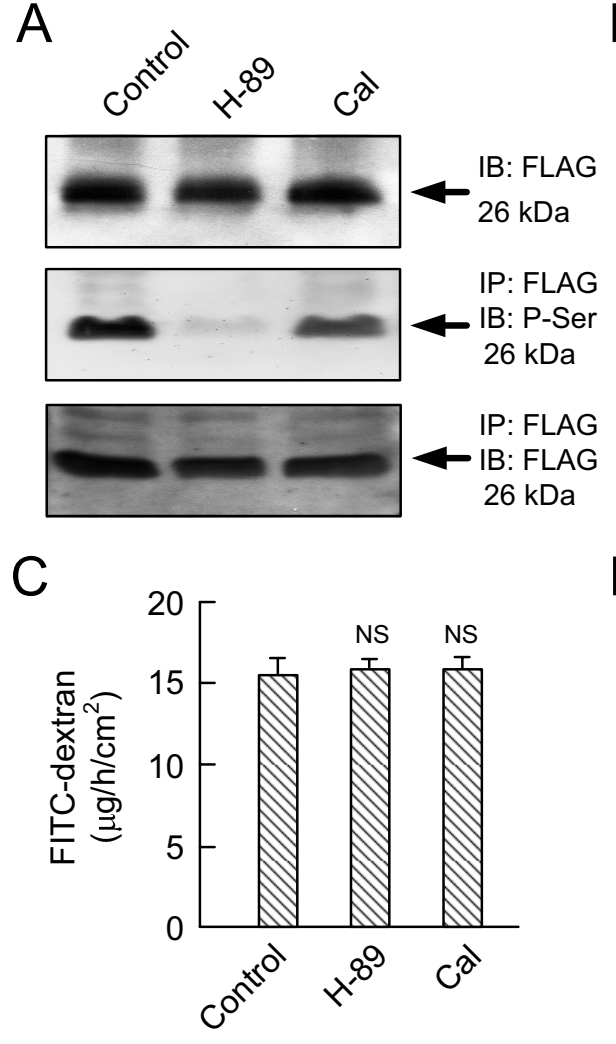

$B$

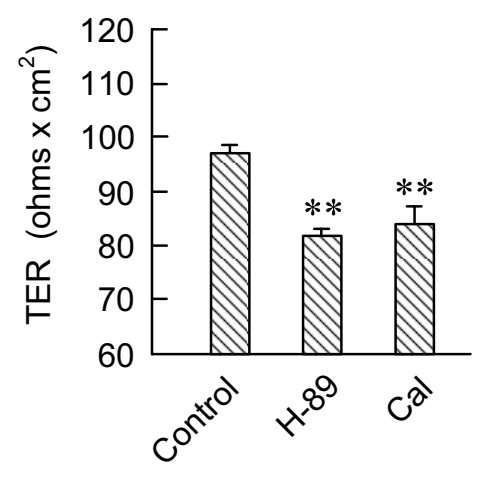

Fig. 2. Dysfunction of paracellin-1 by PKA inhibitor. (A) MDCK cells expressing FLAG-tagged paracellin-1 were treated with $50 \mu \mathrm{M} \mathrm{H}-89$ or $50 \mu \mathrm{M}$ calphostin $\mathrm{C}$ (Cal) for $60 \mathrm{~min}$. The lysates of MDCK cells (30 $\mu \mathrm{g})$ were immunoblotted with antiFLAG antibody (IB: FLAG). The lysates of MDCK cells $(500 \mu \mathrm{g})$ were immunoprecipitated with protein G-Sepharose beads and anti-FLAG antibody. The immune pellets were immunoblotted with anti-phosphoserine (IP: FLAG, IB: P-Ser) or anti-FLAG (IP: FLAG, IB: FLAG) antibodies. (B, C, D) TER values, FITC-dextran diffusion, and transepithelial $\mathrm{Mg}^{2+}$ transport from the apical to the basal compartments were measured in cells treated with $50 \mu \mathrm{M} \mathrm{H}-89$ or 50 $\mu \mathrm{M}$ calphostin $\mathrm{C}$ (Cal) for $60 \mathrm{~min} .{ }^{* *} P<$ 0.01. NS, not significantly different from control.

protein phosphatase $2 \mathrm{~A}(\mathrm{PP} 2 \mathrm{~A})$ activity in the renal cortex was assessed using the Serine/Threonine Phosphatase Assay System (Promega). The value of PPTase-2A activity was determined by absorbance at $630 \mathrm{~nm}$.

Statistics. The results are presented as means \pm SEM. The differences between groups were analyzed by a oneway analysis of variance, and correction for multiple comparisons was made using Tukey's multiple comparison test. Significant differences were assumed at $P<0.05$.

\section{Results and discussion}

A high-salt diet contributes to the development of hypertension, but the cause of salt sensitivity is unknown. Several studies suggest that an inverse relationship exists between dietary $\mathrm{Mg}^{2+}$ intake and blood pressure changes. There is a possibility that an abnormal handling of $\mathrm{Mg}^{2+}$ is involved in the development of hypertension by a highsalt diet. We [5] and others [6] reported that a high-salt diet in DS rats reduces the renal reabsorption of $\mathrm{Mg}^{2+}$. However, the aberrant mechanisms are as yet unclear. Most $\mathrm{Mg}^{2+}$ is suggested to be reabsorbed by paracellin-1 in the TAL. At first we examined the expression and phosphorylation level of paracellin-1. The amount of actin protein was measured as a standard. A high-salt diet had no effect on the expression of paracellin-1 protein in both DR and DS rats (Fig. 1). Preliminarily, a reverse-transcriptase PCR showed that the amount of paracellin-1 mRNA is unaffected by a high-salt diet in both the DR and the DS rats (data not shown). Notably, a high-salt diet decreased the level of serine-phosphorylated paracellin-1 in DS rats, whereas in DR rats it was invariant. These results suggest that the decrease in serine-phosphorylated paracellin-1 is involved in the abnormality of $\mathrm{Mg}^{2+}$ reabsorption in DS rats.

To clarify the significance of phosphorylation, we proceeded to the functional analysis using mammalian expression systems. Several claudins were reported to be phosphorylated by PKA [20, 21] or PKC [22]. Here we used the MDCK cells expressing stably FLAG-tagged paracellin-1. We recently reported that FLAG-tagged paracellin-1 is phosphorylated at serine residue under control conditions and a PKA inhibitor, $N$-[2-( $p$-bromocinnamylamino)ethyl]-5-isoquinolinesulfonamide $\quad(\mathrm{H}-$ 89), decreases the phosphoserine level of paracellin-1 [23]. In contrast, a PKC inhibitor, calphostin C, slightly decreased the phosphoserine level of paracellin-1, but its effect was weaker than that of H-89 (Fig. 2A). The treatment of H-89 or calphostin C did not affect the amount of paracellin-1 protein expression. The effect of $\mathrm{H}-89$ on the FLAG-tagged paracellin-1 in MDCK cells is similar to the decrease in serine-phosphorylated paracellin-1 in DS rats ingesting a high-salt diet, suggesting that a high-salt diet induced the decrease in serine-phosphorylated paracellin1 , mediated via dysfunction of the cAMP/PKA-dependent pathway. Dephosphorylated paracellin-1 is dissociated from the tight junction [23]. We suggest that an abnormality in the localization of paracellin-1 may cause the loss of its original function.

We next examined the effects of protein kinase inhibitors on the function of paracellin-1. H-89 and calphostin C 


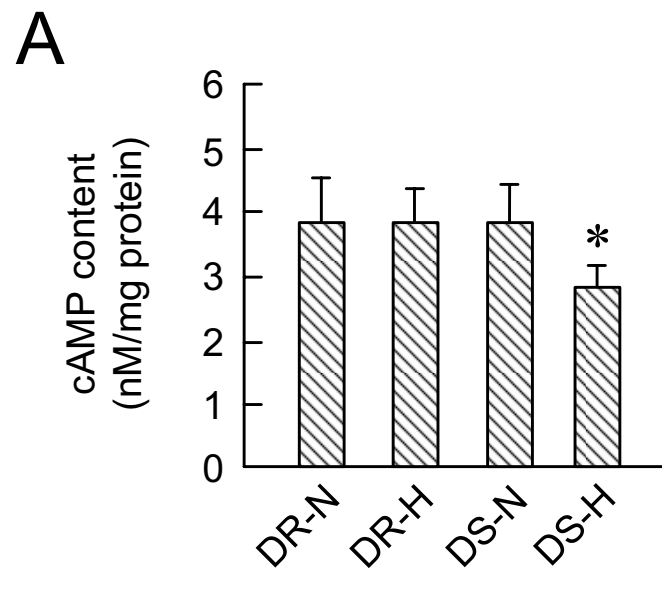

B

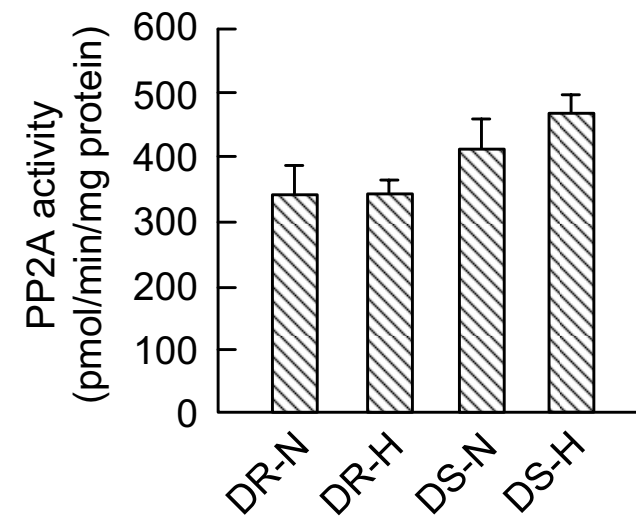

Fig. 3. Decrease of renal cAMP content by a high-salt diet. (A, B) The homogenate of renal cortex was prepared from DR-N, DR-H, DS-N, and DS-H rats. The cAMP content and the PP2A activity were measured as described in MATERIALS AND METHODS. ${ }^{*} P<0.05$.

decreased TER without affecting the paracellular diffusion of FITC-dextran (Fig. 2, B and C). H-89 decreased transepithelial $\mathrm{Mg}^{2+}$ transport, but calphostin $\mathrm{C}$ did not (Fig. 2D). These reports support that paracellin-1 is phosphorylated by PKA, but not by PKC. Although H-89 completely inhibited the phosphorylation of paracellin-1, it decreased transepithelial $\mathrm{Mg}^{2+}$ transport by $25.8 \%$. In untransfected MDCK cells, transepithelial $\mathrm{Mg}^{2+}$ transport was $83.8 \pm 3.0 \mathrm{nmoles} / \mathrm{well} / \mathrm{h}$. This value was equal to that in the paracellin-1-expressing cells treated with $\mathrm{H}-89$. We suggest that paracellin-1-independent $\mathrm{Mg}^{2+}$ transport pathways function in untrasfected cells and the paracellin1-expressing cells treated with $\mathrm{H}-89$.

So far, it has been reported that forskolin, a cAMP agonist, phosphorylated claudin-3 without affecting the amount of claudin-3 protein and decreased in TER in ovarian cancer cells [20]. In contrast, CPT-cAMP, a cAMP analog, increased in the expression of claudin-5 and TER in endothelial cells [21]. Thus the response of claudins against cAMP is different in the types of claudins. In
MDCK and LLC-PK 1 cells, each exogenous claudin showed its own unique ion selectivity, and overexpession would overwhelm the endogenous claudins, thus making the final paracellular selectivity independent of the cell background [17]. We suggest that phosphorylated paracellin-1 made an $\mathrm{Mg}^{2+}$ permeable pore mediated by homophilic interactions paracellin-1 itself or heterophilic interactions between paracellin-1 and other claudins.

Protein phosphorylation and dephosphorylation are carried out by kinases and phosphatases, respectively. Umemura et al. [12] reported that urinary cAMP excretion and the renal adenylate cyclase response to parathyroid hormone are lower in DS than in DR rats at the ages of 3-32 weeks. This suggests that the renal cAMP content is lower in DS than in DR rats. Notably, we found that the cAMP content of renal cortex in DS rats ingesting a highsalt diet was lower than those in DS rats ingesting a normal-salt diet and in DR rats ingesting normal- and highsalt diets (Fig. 3A).

The reduction of serine-phosphorylated paracellin-1 might be caused not only by the decrease in cAMP content (PKA activity), but also by the increase in protein phosphatases, which are divided into two large groups: protein serine/threonine and tyrosine phosphatases [24, 25]. PP2A accounts for the major portion of serine/threonine phosphatase activity in most tissues and cells. Therefore we examined the PP2A activity in the renal cortex. In DS rats ingesting a high-salt diet, it was slightly higher than in other groups, but it was not significant (Fig. 3B). In spontaneously hypertensive rats, PP2A activity is not different from that in normotensive Wistar-Kyoto rats [26]. We suggest that PP2A activity does not closely relate to the regulation of renal cAMP content in hypertensive rats. At present, we cannot deny the involvement of other protein phosphatases such as PP1, PP2B, and PP2C because of the lack of selective inhibitors/activators for different protein phosphatases. The increase of Gi alpha- 2 and Gi alpha-3 proteins preceded the development of blood pressure in DOCA-salt hypertensive rats [27], indicating that the decrease in the cAMP level is a factor that contributes to hypertension. In contrast, tubular $\mathrm{Mg}^{2+}$ reabsorption is upregulated by various hormones acting through cAMP production [28]. Therefore the renal cAMP content may be a key factor for the regulation of $\mathrm{Mg}^{2+}$ reabsorption and blood pressure.

In conclusion, we found that paracellin-1 is dephosphorylated in DS rats ingesting a high-salt diet. The phosphorylation of paracellin-1 is upregulated by PKA, but not by PKC. The functions of paracellin-1 such as an $\mathrm{Mg}^{2+}$ permeable pore appeared when paracellin-1 was phosphorylated by a cAMP/PKA-dependent pathway. The cAMP content of renal cortex in DS rats ingesting a high-salt diet was lower than in other groups. Although we cannot deny the involvement of other regulatory factors, the reduction of phosphorylated paracellin-1 may be caused by the im- 
paired function of cAMP/PKA-dependent hormonal regulation in DS rats. The reduction of phosphorylated paracellin-1 may result in the decrease of magnesium reabsorption in DS rats.

This work was supported in part by the Ministry of Education, Science, Sports and Culture of Japan, a Grant-in-Aid for the Encouragement of Young Scientists (to A.I.), and by grants from the Salt Science Research Foundation, No. 0525, and the Takeda Science Foundation (to A.I.).

\section{REFERENCES}

1. Milan A, Mulatero P, Rabbia F, Veglio F. Salt intake and hypertension therapy. J Nephrol. 2002;15:1-6.

2. Buemi M, Senatore M, Corica F, Aloisi C, Romeo A, Tramontana D, Frisina N. Diet and arterial hypertension: is the sodium ion alone important? Med Res Rev. 2002;22:419-28

3. Haddy FJ, Pamnani MB. Role of dietary salt in hypertension. J Am Coll Nutr. 1995;14: 428-38.

4. Rapp JP. Dahl salt-susceptible and salt-resistant rats. A review. Hypertension. 1982:4:753-63

5. Ikari A, Kano T, Suketa Y. Magnesium influx enhanced by nitric oxide in hypertensive rat proximal tubule cells. Biochem Biophys Res Commun. 2002;294:710-3.

6. Wu X, Ackermann U, Sonnenberg H. Potassium depletion and salt-sensitive hypertension in Dahl rats: effect on calcium, magnesium, and phosphate excretions. Clin Exp Hypertens. 1995;17:989-1008.

7. Berthon N, Laurant P, Fellmann D, Berthelot A. Effect of magnesium on mRNA expression and production of endothelin- 1 in DOCA-salt hypertensive rats. $J$ Cardiovasc Pharmacol. 2003;42:24-31

8. Reeta K, Madhu K, Manoj K, Promila P, Roma U. Effect of oral magnesium supplementation on blood pressure, platelet aggregation and calcium handling in deoxycorticosterone acetate induced hypertension in rats. J Hypertens. 2000;18:919-26.

9. Widman L, Wester PO, Stegmayr BK, Wirell M. The dose-dependent reduction in blood pressure through administration of magnesium. A double blind placebo controlled cross-over study. Am J Hypertens. 1993;6:41-5.

10. Mizushima S, Cappuccio FP, Nichols R, Elliott P. Dietary magnesium intake and blood pressure: a qualitative overview of the observational studies. J Hum Hypertens. 1998;12:447-53.

11. Kawano $Y$, Matsuoka H, Takishita S, Omae T. Effects of magnesium supplementation in hypertensive patients: assessment by office, home, and ambulatory blood pressures. Hypertension. 1998;32:260-5.

12. Umemura S, Smyth DD, Nicar M, Rapp JP, Pettinger WA. Altered calcium homeostasis in Dahl hypertensive rats: physiological and biochemical studies. J Hypertens. 1986;4:19-26.
13. Rouffignac $C$ de, Quamme GA,. Renal magnesium handling and its hormonal control. Physiol Reviews. 1994;74:305-322.

14. Simon DB, Lu Y, Choate KA, Velazquez H, Al-Sabban E, Praga M, Casari G, Bettinelli A, Colussi G, Rodriguez-Soriano J, McCredie D, Milford D, Sanjad S, Lifton RP. Paracellin-1, a renal tight junction protein required for paracellular $\mathrm{Mg}^{2+}$ resorption. Science. 1999;285:103-6.

15. Ikari A, Hirai N, Shiroma M, Harada H, Sakai H, Hayashi H, Suzuki Y, Degawa M, Takagi K. Association of paracellin-1 with ZO-1 augments the reabsorption of divalent cations in renal epithelial cells. J Biol Chem. 2004;279:54826-32.

16. Colegio OR, Van Itallie $C$, Rahner $C$, Anderson JM. Claudin extracellular domains determine paracellular charge selectivity and resistance but not tight junction fibril architecture. American Journal of Physiology Cell Physiology. 2003:284:C1346-54.

17. Van Itallie CM, Fanning AS, Anderson JM. Reversal of charge selectivity in cation or anion-selective epithelial lines by expression of different claudins. American Journal of Physiology Renal Physiology. 2003;285:F1078-84.

18. Yu AS, Enck AH, Lencer WI, Schneeberger EE. Claudin-8 expression in MadinDarby canine kidney cells augments the paracellular barrier to cation permeation. J Biol Chem. 2003;278:17350-9.

19. Molitoris BA, Simon FR. Renal cortical brush-border and basolateral membranes: cholesterol and phospholipid composition and relative turnover. J Membr Biol. 1985;83:207-15.

20. D'Souza T, Agarwal R, Morin PJ. Phosphorylation of claudin-3 at threonine 192 by PKA regulates tight junction barrier function in ovarian cancer cells. J Biol Chem. 2005;280:26233-40.

21. Soma T, Chiba H, Kato-Mori Y, Wada T, Yamashita T, Kojima T, Sawada N. $\operatorname{Thr}(207)$ of claudin- 5 is involved in size-selective loosening of the endothelial barrier by cyclic AMP. Exp Cell Res. 2004;300:202-12.

22. Nunbhakdi-Craig V, Machleidt T, Ogris E, Bellotto D, White CL, Sontag E. Protein phosphatase $2 A$ associates with and regulates atypical PKC and the epithelial tight junction complex. J Cell Biol. 2002;158:967-78.

23. Ikari A, Matsumoto S, Harada H, Takagi K, Hayashi H, Suzuki Y, Degawa M, Miwa M. Phosphorylation of paracellin-1 at Ser217 by protein kinase $A$ is essential for localization in tight junctions. J Cell Sci. 2006;119:1781-9.

24. Mumby MC, Walter G. Protein serine/threonine phosphatases: structure, regulation, and functions in cell growth. Physiol Rev. 1993;73: 673-99.

25. Stoker AW. Protein tyrosine phosphatases and signalling. J Endocrinol. 2005;185:19-33.

26. Yu P, Asico LD, Eisner GM, Hopfer U, Felder RA, Jose PA. Renal protein phosphatase $2 A$ activity and spontaneous hypertension in rats. Hypertension. 2000;36:1053-8.

27. Marcil J, de Champlain J, Anand-Srivastava MB. Overexpression of Gi-proteins precedes the development of DOCA-salt-induced hypertension: relationship with adenylyl cyclase. Cardiovasc Res. 1998:39:492-505.

28. Quamme GA. Control of magnesium transport in the thick ascending limb. Am J Physiol. 1989;256:F197-210. 